\begin{tabular}{|c|c|c|c|}
\hline Article Info & \multicolumn{2}{|c|}{\begin{tabular}{l|l} 
RESEARCH ARTICLE & ARAŞTIRMA MAKALESI
\end{tabular}} & \\
\hline Title of Article & \multicolumn{2}{|c|}{$\begin{array}{c}\text { Temporal and Spatial Change of Land Use: } \\
\text { The Case of Nazilli District }\end{array}$} & \\
\hline $\begin{array}{l}\text { Corresponding } \\
\text { Author }\end{array}$ & \multicolumn{2}{|c|}{$\begin{array}{l}\text { Assist Prof. Özgür Burhan Timur } \\
\text { Çankırı Karatekin University Landscape Architecture Department / Çankırı Karatekin } \\
\text { Üniversitesi Peyzaj Mimarlı̆ı̆ Bölümü, ozgurtim@ @otmail.com }\end{array}$} & \\
\hline $\begin{array}{l}\text { Received Date } \\
\text { Accepted Date }\end{array}$ & \multicolumn{2}{|c|}{$\begin{array}{l}27.12 .2020 \\
10.02 .2021\end{array}$} & \\
\hline Author / Authors & $\begin{array}{l}\text { Özgür Burhan Timur } \\
\text { İbrahim Aytaş } \\
\text { Burhan Acet }\end{array}$ & $\begin{array}{l}\text { ORCID: 0000-0003-0626-3031 } \\
\text { ORCID: 0000-0002-0997-5862 } \\
\text { ORCID: 0000-0003-3837-3876 }\end{array}$ & \\
\hline How to Cite & \multicolumn{2}{|c|}{$\begin{array}{l}\text { Timur, Ö.B., Aytaş İ., Acet B. (2021). Temporal and Spatial Change of Land Use: The } \\
\text { Case of Nazilli District, Kent Akademisi, Volume, } 14 \text { (43), Issue 1, Pages, 230-240 }\end{array}$} & $\begin{array}{l}\text { Kent Akademisi } \\
\text { Urbban Academy }\end{array}$ \\
\hline
\end{tabular}

\title{
Arazi Kullanımının Zamansal ve Mekânsal Değişimi: Nazilli İlçesi Örneği
}

Özgür Burhan Timur ${ }^{1}$ İbrahim Aytaş ${ }^{2}$ Burhan Acet $^{3}$

\begin{abstract}
:
Today, unplanned urbanization has gained increasing momentum as a result of rapid population growth and distorted construction. In order to prevent this, it is of great importance to determine the current situation of the land uses by determining them temporally and spatially. Its' one of the most convenient and realistic ways is landuse change monitoring techniques using satellite images.

In this study, satellite images were analyzed by using Geographical Information Systems in Nazilli District of Aydin province (approximately $2919 \mathrm{ha}$ ), spatial and temporal changes of land cover/land use (LC/LU) were determined. Using the Google Earth satellite imagery of the district in 2004 and 2019, manual classification was made with ArcGIS 10.5 program, five main LC/LU classes were created and digitized. The data obtained were compared and the change of LC/LU of the district center in 15 years period was determined. According to the results; while the agricultural areas had an area of 1643,80 ha in 2004, these areas were calculated as 1243,96 ha in 2019. The residential and industrial areas which were 996,31 ha in 2004 increased to 1139,38 ha in 2019. The total amount of active and passive green areas in the area increased from 215.06ha in 2004 to 327.40ha in 2019. In the research, the reasons of this change were examined and suggestions were made.
\end{abstract}

Keywords: Land use, land cover, geographical information systems, Nazilli, landscape change, remote sensing

${ }^{1}$ Çankırı Karatekin University Forest Faculty Landscape Architecture Department, ozgurim@ hotmail.com

${ }^{2}$ Çankırı Karatekin University Forest Faculty Landscape Architecture Department, aytasibrahim@karatekin.edu.tr

${ }^{3}$ Çankırı Karatekin University Institute of Science, burhanacet@hotmail.com 


\section{ÖZ:}

Günümüzde, hızlı nüfus artışı ve çarpık yapılaşma sonucunda, plansız kentleşme giderek artan bir ivme kazanmaktadır. Plansız kentleşmenin önlenmesinde, alan kullanımlarının mevcut durumunun zamansal ve mekânsal olarak belirlenerek değerlendirilmesi büyük önem taşımaktadır. Çalışmayı uygulamanın en uygun ve gerçekçi yollarından birisi ise uydu görüntüleri kullanılarak yapılan arazi değişim izleme tekniklerini kullanmaktır. $\mathrm{Bu}$ çalışmada, Aydın İli Nazilli İlç̧esi'nde (yaklaşık olarak 2919 ha alanda) Coğrafi Bilgi Sistemleri kullanılarak, uydu görüntüleri incelenmiş ve arazi örtüsü/alan kullanımının (AÖ/AK) mekânsal ve zamansal değişimi belirlenmiştir. İlçenin 2004 ve 2019 yıllarına ait Google Earth uydu görüntüleri kullanılarak, ArcGIS 10.5 programı aracıllğıyla manuel sınıflandırma yapılmış, beș ana AÖ/AK sınıfı oluşturulmuş ve sayısallaştırma yapılmıştır. Elde edilen veriler karşılaştırılarak, ilçe merkezinin 15 yıllık süreçteki arazi örtüsü/alan kullanımının(AÖ/AK) değişimi tespit edilmiştir. Sonuçlara göre; 2004 yılında tarımsal alanlar 1643,80 ha alana sahipken, 2019 yılında bu alanlar 1243,96 ha olarak hesaplanmıştır. 2004 yılında 1060,11 ha olan sanayi ve yerleşim alanları, 2019 yılında 1347,59 ha'a çıkmıştır. Alandaki aktif ve pasif yeşil alanın toplam miktarı 2004 yılında 215,06 ha iken 2019 yılında 327,40 ha'a yükselmiştir. Araştırmada, kullanım alan miktarlarının değişim nedenleri irdelenerek, önerilerde bulunulmuştur

ANAHTAR KELIMELER: Alan kullanımı, arazi örtüsü, coğrafi bilgi sistemleri, Nazilli, peyzaj değişimi, uzaktan algilama.

\section{“Arazi Kullanımının Zamansal ve Mekânsal Değişimi: Nazilli İlçesi Örneği”}

\section{GİRIŞ:}

Günümüzde gerçekleşen hızlı nüfus artışı ve düzensiz kentleşmenin etkisi ile doğal kaynaklar ciddi baskılar görmekte ve alan kullanım sınırları değişmektedir. Arazi kullanımlarına yönelik olarak yapılan hatalı uygulamalar veya yanlış yaklaşımlar da peyzajın yapısında bozulmalara ve tahribata yol açabilmektedir. Peyzajdaki bu tahribatın yine o peyzajda yaşayan tüm canlı organizmalara uzun ya da kısa vadede ve dolaylı ya da doğrudan olumsuz etkileri olabilmektedir. Örneğin; alt ölçekte bir orman peyzajında yaşayan toprak solucanı popülasyonunda düzensiz ağaç kesimi sonrasında görülen bir azalma, üst ölçekte bölge topraklarında verimsizleşmeye kadar uzanabilen bir dizi ekolojik soruna yol açabilecektir. Tıpkı bunun gibi, orman, mera, sucul ekosistemler, akarsu zonları gibi doğal peyzajların tahribatı sonucunda toprak, su, hava, flora, fauna gibi doğal kaynaklar yoğun bir baskıyla karşı karşıya kalmaktadır (Gülersoy, 2008).

Yüksek eğimli heyelan bölgelerindeki ormanların yok edilmesinin yanında, üst toprağın oluşumunu büyük ölçüde hızlandıran vejetatif örtünün ve orman arazisinin tarımsal üretim alanlarına ve bahçecilik işletmelerine dönüştürülmesi gibi faaliyetler, arazi kullanımında ve dolayısıyla arazi örtüsünde değişikliklere yol açmaktadır (Khan vd., 2017).

Arazi kullanımı/örtüsü değişiminin ekosistem hizmetleri üzerindeki etkilerini geniş bir yelpazede inceleyen ya da tanımlayan bazı akademik çalışmalar (Vitousek, 1997; Sala vd., 2000; Trimble ve Crosson, 2000; Praveen, 2017), küresel ölçekteki sorunların; (1)biyotik çeşitlilik üzerindeki etkiler, (2)toprak bozulması ve (3)ekosistemlerin insan ihtiyaçlarını destekleme kabiliyeti üzerinde yoğunlaştığını ortaya koymaktadır.

Sürdürülebilirlik yaklaşımının dışındaki her türden insan faaliyeti, suyun, toprağın ve havanın kalitesini düşürdüğü gibi gıdaya erişimi de zorlaştırmaktadır. Bu nedenle, alan kullanım planlamasının yapılması ve ekosistem hizmetine erişebilirlik hakkında bir anlayış oluşturmak, toplulukların hayatta kalması için son derece önemli kriterlerdir (Ding vd., 2015; Parveen vd., 2018). Bu nedenlerden dolayı, Gülersoy (2013a), doğal kaynakların gelecek nesillere doğru bir şekilde aktarılması için alanların amacı dışında, bilinçsiz kullanımını önlemek ve peyzaj desenindeki değişimleri izlemek amacıyla alan kullanımındaki zamansal ve mekânsal değişimlerin tespit edilmesinin önemini vurgulamaktadir.

Son yıllarda, dünyanın birçok yerindeki peyzajlar, biyolojik çeşitliliği ve insan refahını tehdit eder biçimde ve benzeri görülmemiş oranlarda dönüştürülmektedir (Antrop 2000; Steiner 2016). Kırsal alanların kentsel ve endüstriyel kullanım alanlarına dönüştürülmesi gelişmekte olan ülkelerin önemli bir sorunu haline gelmiştir. Türkiye'de 1991- 
2001 yılları arasında yaklaşık 131,38 hektar verimli tarım arazisi kentsel alanlara ve turizm alanına dönüştürülmüştür (TUIK, 2001).

Plansız kentleşmenin önlenmesinde, alan kullanımlarının mevcut durumunun zamansal ve mekânsal olarak belirlenerek değerlendirilmesi konusu önemli bir rol oynamaktadır. Bunun en uygun ve gerçekçi yollarından birisi de uydu görüntüleri kullanılarak yapılan değişim izleme teknikleridir (Cürebal vd., 2008). Uzaktan algılama teknikleri kullanılarak mevcut arazi kullanımlarının belirlenmesi, analizi ve multidisipliner çalışmalarla oluşturulan arazi kullanım planlamaları için büyük bir önem taşımaktadır (Gülersoy, 2013a).

$\mathrm{Bu}$ çalışmanın amacı; Nazilli ilçesinin arazi örtüsü/alan kullanımlarının mekânsal ve zamansal değişimini belirleyerek, ilçe merkezindeki arazi kullanım değiş̧ikliklerinin belirlenmesidir. İlçenin araştırma alanı olarak seçilmesinin nedeni ise; Deniz'in (2013) de belirttiği gibi, ilçe merkez nüfusunun köylerden olan göçle birlikte giderek artması sonucu konut yoğunluğunun artması ve dolayısıyla bu durumun ilçe merkezinin etrafindaki önemli ekonomik girdiye sahip tarım alanlarını da tehdit eder hale gelmesidir. Bu baskıya merkezde yoğunlaşan sanayi kuruluşlarının özellikle Büyük Menderes nehrine ve onu besleyen diğer akarsularla bunların etrafındaki tarım arazilerine olan kirletici etkileri de eklendiğinde, bölgenin alan kullanımlarındaki değişimlerinin anlaşılması gerektiği açıktır.

\section{MATERYAL ve YÖNTEM}

\section{Çalışma Alanı}

Çalışma alanı, Ege Bölgesi’nin kuzeydoğusunda yer alan Aydın iline bağlı ve yaklaşık 664 km2 yüzölçümlü Nazilli merkez ilçe sınırları içerisinde kent merkezi ve kent merkeziyle bağlantılı yakın çevresini kapsamaktadır (Şekil 1). $37^{\circ} 55^{\prime}$ kuzey enleminde yer alan ilçenin rakımı 60 ile 1600 metre arasında olup, kuzey kesiminde Aydın Dağları, güney kesiminde ise Karıncalı Dağı yer almaktadır. Büyük Menderes Havzası'nın orta mecrasında bulunan ilçe merkezi, bölgenin en uzun akarsuyu niteliğindeki Büyük Menderes Nehri'nin kuzey kesimlerindeki alüvyal ve kolüvyal topraklar üzerine kuruludur. Alanın denize uzaklığı yaklaşık olarak $104 \mathrm{~km}$ olup, Thornthwaite iklim sinıflandırmasına (MGM, 2020) göre; yarı kurak-az nemli, mezotermal iklim tipine sahiptir. Alandaki yıllık ortalama sıcaklık 17,5 oC iken, yıllık ortalama yağış miktarı ise 569 mm civarındadır (Deniz, 2013; ÇŞB, 2020).

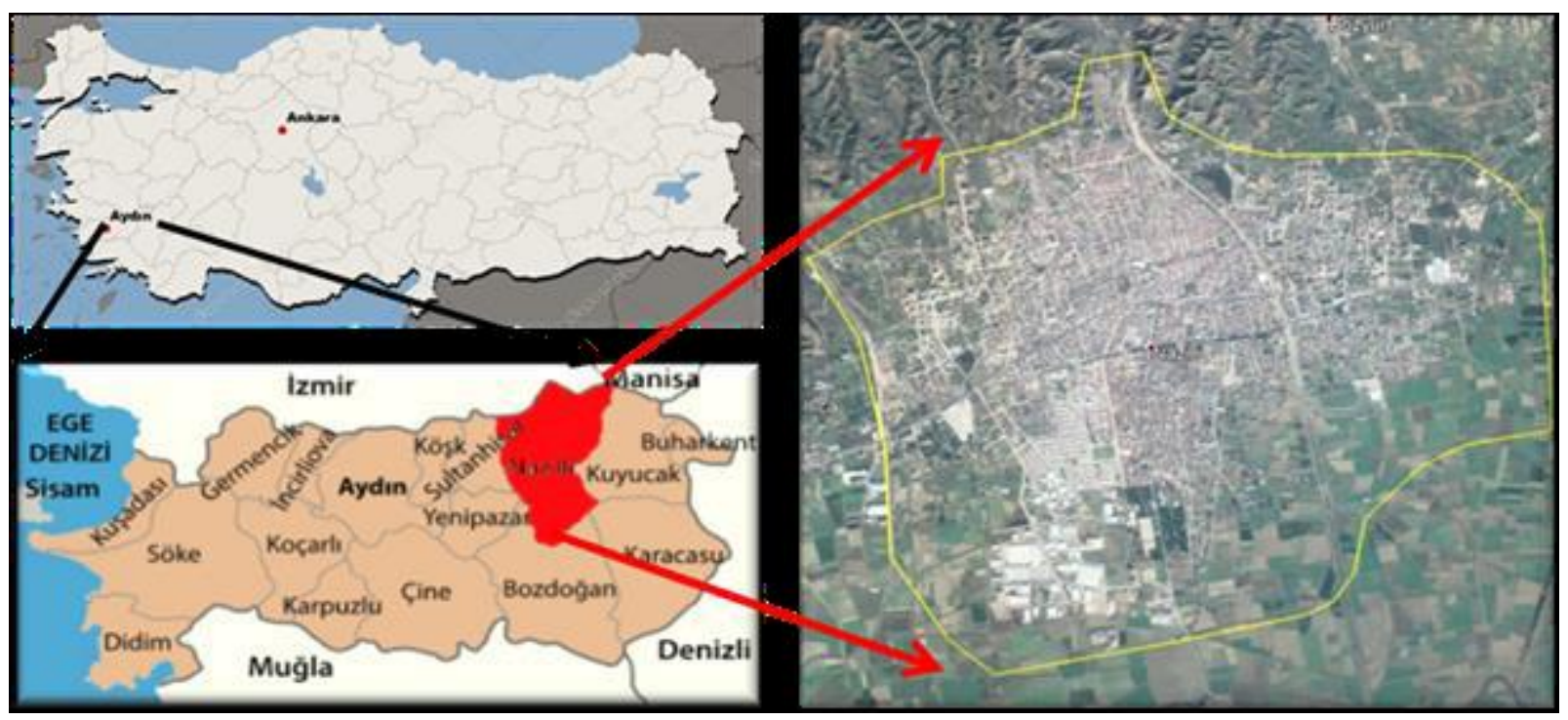

Şekil 1. Çalışma alanının konumu ve sınırları

Araştırma sahası, ılıman karakterdeki Akdeniz iklim tipinin ve Akdeniz fitocoğrafya bölgesinin içinde yer almaktadır. Alanın da içerisine dâhil olduğu maki bitki toplulukları bölgesindeki bazı başlıca bitki türleri; Pinus brutia, Pinus 
nigra subsp. Pallasiana, Quercus sp., Castanea sativa, Salix sp., Junglans regia, Platanus orientalis, Quercus coccifera, Pistacia terebintus, Calicotome villosa, Phillyrea latifolia, Arbutus unedo, Laurus nobilis, Olea europaea, Nerium olender, Vitex agnus castus ve Spartium junceum, Origonum orites, Corido thymus, Thymbra spicata'dir (Deniz, 2013).

TUİK' in (2020) güncellenmiş verilerine göre toplam nüfusu 159544 olan ilçenin nüfusunun büyük bölümü sanayi ve hizmet sektöründe istihdam edilirken, tarım ise hem nüfusun doğrudan önemli bir geçim kaynağı hem de diğer sektörleri destekleyen bir faaliyet konumundadır. İlçenin en önemli zirai ürünleri ise incir, üzüm, narenciye, zeytin, pamuk, arpa, buğday ve meyan kökü olarak sıralanabilir. Tarım ürünleri içinde yer alan pamuk yetiştiriciliği, Nazilli ilçesi için geçmişten günümüze kadar önemli bir geçim kaynağı olmuştur (Deniz, 2013; ÇŞB, 2020).

\section{Materyal}

Çalışmada materyal olarak, 2004 ve 2019 yılları olmak üzere iki farklı tarihe ait Google Earth Pro uydu görüntüleri kullanılmıştır. Araştırmada, alan kullanımları hazırlanırken ArcGIS 10.5 CBS yazılımından yararlanılmıştır. Konuya ilişkin kitap, makale, tez, vb. akademik çalışmalardan yardımıı materyal olarak yararlanılmıştır.

\section{Yöntem}

AÖ/AK değişimini belirlemek için mevcut durum belirlenmiş daha sonra önceki uydu görüntüleri kullanılarak değişimler tespit edilmiştir. (Güre vd., 2009).

Çalışmada ilk olarak, CORINE arazi örtüsü sınıfları içerisinde ve alanının AÖ/AK doğrultusunda Çizelge 1'de olduğu gibi yeniden bir değerlendirme yapılmış ve arazi örtüsü 5 farklı sınıfa ayrılmıştır.

Çizelge 1. CORINE arazi örtüsü sınıflarının yeniden düzenlenmesi (Bayar ve Karabacak 2017'den değiştirilerek)

\begin{tabular}{|l|l|}
\hline Arazi Örtüsü Sınıfları & CORINE Arazi Örtüsü Sınıfları İçerisindeki Yeri \\
\hline Sanayi & Yerleşim bölgesinden çıkartılmıştır \\
\hline Sulak Alanlar & Akarsular, su yapıları ve su kütleleri ile birleştirilmiştir. \\
\hline Tarımsal Alanlar & Tarımsal alanlardan çayır alanları çıkartılmıştır. \\
\hline Yerleşim Alanları & Yapısal alanlar, yollar ile birleştirilmiştir. \\
\hline Yeşil Alanlar & Çayır alanları ile birleştirilmiştir. \\
\hline
\end{tabular}

Bu sınıflar dikkate alınarak Aydın ili Nazilli İlçesi’nin 2004 ve 2019 yıllarına ait arazi örtüsü haritaları ArcGIS 10.5 programı yoluyla manuel/görsel sınıflandırma yöntemiyle oluşturularak arazi örtüsündeki değişim oranları alansal olarak ortaya konulmuştur. Manuel/görsel sınıflandırma yöntemi, otomatik sınıflandırma yöntemlerine göre sonuca ulaşmada daha yavaş olmasına rağmen, görüntüdeki renk, ton, doku, desen vb. tüm bileşenler dikkate alındığı için otomatik sınıflandırma yöntemine göre daha avantajlıdır. Oysa otomatik yöntemler sadece görüntüdeki piksel değerlerine (tonal özelliklerine) göre sınıflandırma yapar. Manuel yöntemde ise sınıflandırmayı yapan araştırmacı değerlendirme yaparken geçmişteki tüm birikimini de kullanır (KHGM, 2001). Alanın arazi kullanımlarının zamansal ve mekânsal değişimi, birçok araştırmacının çalışmalarında kullandıkları metadoloji referans alınarak (Richards, 1995; Dengiz ve Sarığlu, 2011; Everest vd., 2011; Kurt vd., 2011; Kara ve Karatepe, 2012; Oğuz ve Zengin, 2011; Bayar ve Karabacak, 2017) hazırlanmıştır. 
Çalışmada, 2004-2019 yıllarına ait uydu görüntülerinden elde edilen sınıflandırılmış sayısal haritalar alan (ha) ve yüzde (\%) olarak tablo haline dönüştürülmüş̧ür. Sonrasında ise, Nazilli ilçesinde 15 ylllık periyotta alan kullanımlarında süregelen değişimler ortaya konularak değerlendirilmiş ve bazı önerilerde bulunulmuştur.

\section{BULGULAR ve TARTIŞMA}

Uydu görüntülerinin analizi sonucunda çalışma alanının 2004 yılına ait arazi kullanımları Çizelge 2'de, 2019 yılına ait arazi kullanımları ise Çizelge 3 'te verilmiştir.

Çizelge 2. Nazilli ilçesinin 2004 yılına ait alan kullanımlarının dağılımı

\begin{tabular}{|l|l|l|}
\hline Alan Kullanımları & Alan (ha) & Alan (\%) \\
\hline Sanayi Alanları & 63,80 & 2,19 \\
\hline Sulak Alanlar & 31,96 & 1,09 \\
\hline Tarımsal Alanlar & 1643,80 & 56,31 \\
\hline Yerleşim Alanları & 996,31 & 34,13 \\
\hline Yeşil Alanlar & 183,10 & 6,27 \\
\hline Toplam & 2918,97 & 100,00 \\
\hline
\end{tabular}

2004 yılı arazi kullanımları analizine göre; en fazla yayılış gösteren alan sınıfı, tarımsal alanlar olarak tespit edilmiştir. Tarım alanlarını sırasıyla yerleşim alanları, yeşil alanlar, sanayi alanları ve sulak alanlar takip etmektedir.

Çizelge 3. Nazilli ilçesinin 2019 yılına ait alan kullanımlarının dağılımı

\begin{tabular}{|l|l|l|}
\hline Alan Kullanımları & Alan (ha) & Yüzde (\%) \\
\hline Sanayi Alanları & 208,21 & 7,13 \\
\hline Sulak Alanlar & 23,94 & 0,82 \\
\hline Tarımsal Alanlar & 1243,96 & 42,62 \\
\hline Yerleşim Alanları & 1139,38 & 39,03 \\
\hline Yeşil Alanlar & 303,46 & 10,40 \\
\hline Toplam & 2918,97 & 100,00 \\
\hline
\end{tabular}

2019 yılı arazi kullanımları değerlendirildiğinde; tarım alanlarında düşüş, yerleşim ve sanayi alanlarında ise artış olduğu belirlenmiştir (Çizelge 3). Çalışma alanının 2004 ve 2019 yıllarına ilişkin alan kullanım haritaları Şekil 2'de verilmiştir. 

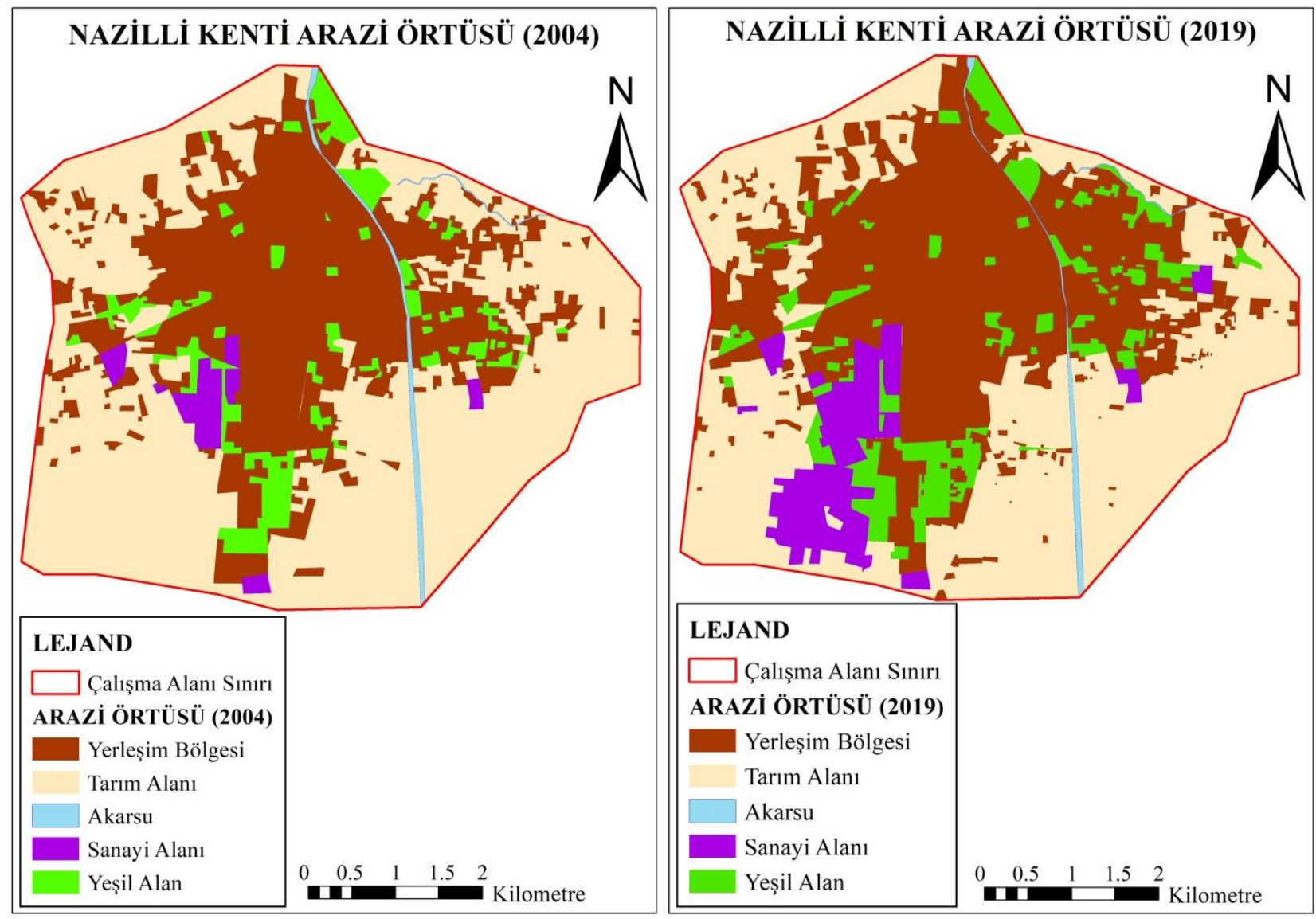

Şekil 2. 2004 yılına ait arazi örtüsü haritası (solda), 2019 yılına ait alan kullanımları haritası (sağda)

Analiz sonucunda Nazilli ilçesinin alan kullanımlarındaki zamansal ve mekânsal değişim alan (ha) ve yüzde (\%) olarak belirlenmişsir. Çalışma alanının 2004-2019 yılları arasındaki arazi örtüsü/arazi kullanımları değişimi Tablo 4'te verilmiştir.

Çizelge 4. 2004-2019 yılları arası arazi örtüsü/arazi kullanımları değişimi

\begin{tabular}{|c|c|c|c|c|c|c|}
\hline \multirow{2}{*}{ Alan Kullanımı } & \multicolumn{2}{|l|}{2004} & \multicolumn{2}{|l|}{2019} & \multicolumn{2}{|l|}{ Değişim } \\
\hline & Alan (ha) & Alan (\%) & Alan (ha) & Alan (\%) & Alan (ha) & Alan (\%) \\
\hline Sanayi Alanları & 63,80 & 2,19 & 208,21 & 7,13 & 144,41 & 4,95 \\
\hline Sulak Alanlar & 31,96 & 1,09 & 23,94 & 0,82 & $-8,01$ & $-0,27$ \\
\hline Tarımsal Alanlar & 1643,80 & 56,31 & 1243,96 & 42,62 & $-399,83$ & $-13,70$ \\
\hline Yerleşim Alanları & 996,31 & 34,13 & 1139,38 & 39,03 & 143,07 & 4,90 \\
\hline Yeşil Alanlar & 183,10 & 6,27 & 303,46 & 10,40 & 120,36 & 4,12 \\
\hline Toplam & 2918,97 & 100,00 & 2918,97 & 100,00 & 0,00 & 0,00 \\
\hline
\end{tabular}

Title of Your Article 
2004-2019 yılları arasında incelenen alan kullanımları değişiminde sanayi alanları, yerleşim alanları ve yeşil alanların arttığı, tarımsal alanların ve sulak alanların azaldığı tespit edilmiştir. Buna göre; 15 yıllık süreçte, tarım alanları \% 13,70 oranında azalma göstermiştir. Yıllara göre gerçekleşen nüfus artışından dolayı yerleşim alanlarında da artış olduğu belirlenmiştir. 2004 yılında 996,31 ha alan kaplayan yerleşim alanları, 2019 yılında 1139,38 ha alana yükselmiştir. Gerçekleşen nüfus artışı ve hızlı kentleşmenin etkisi ile verimli tarım alanlarının yok edilerek, bu bölgelerin sanayi ve yerleşim alanlarına dönüştürüldüğ̈̈ tespit edilmiştir.

Çalışma alanına ilişkin 2004 ve 2019 yıllarına ait sayısallaştırılmış yerleşim haritaları (Şekil 3) incelendiğinde; yerleşim alanlarının hastanenin de içinde bulunduğu Doğu ve Batı yönünde \% 4,90 oranında arttığı tespit edilmiştir.
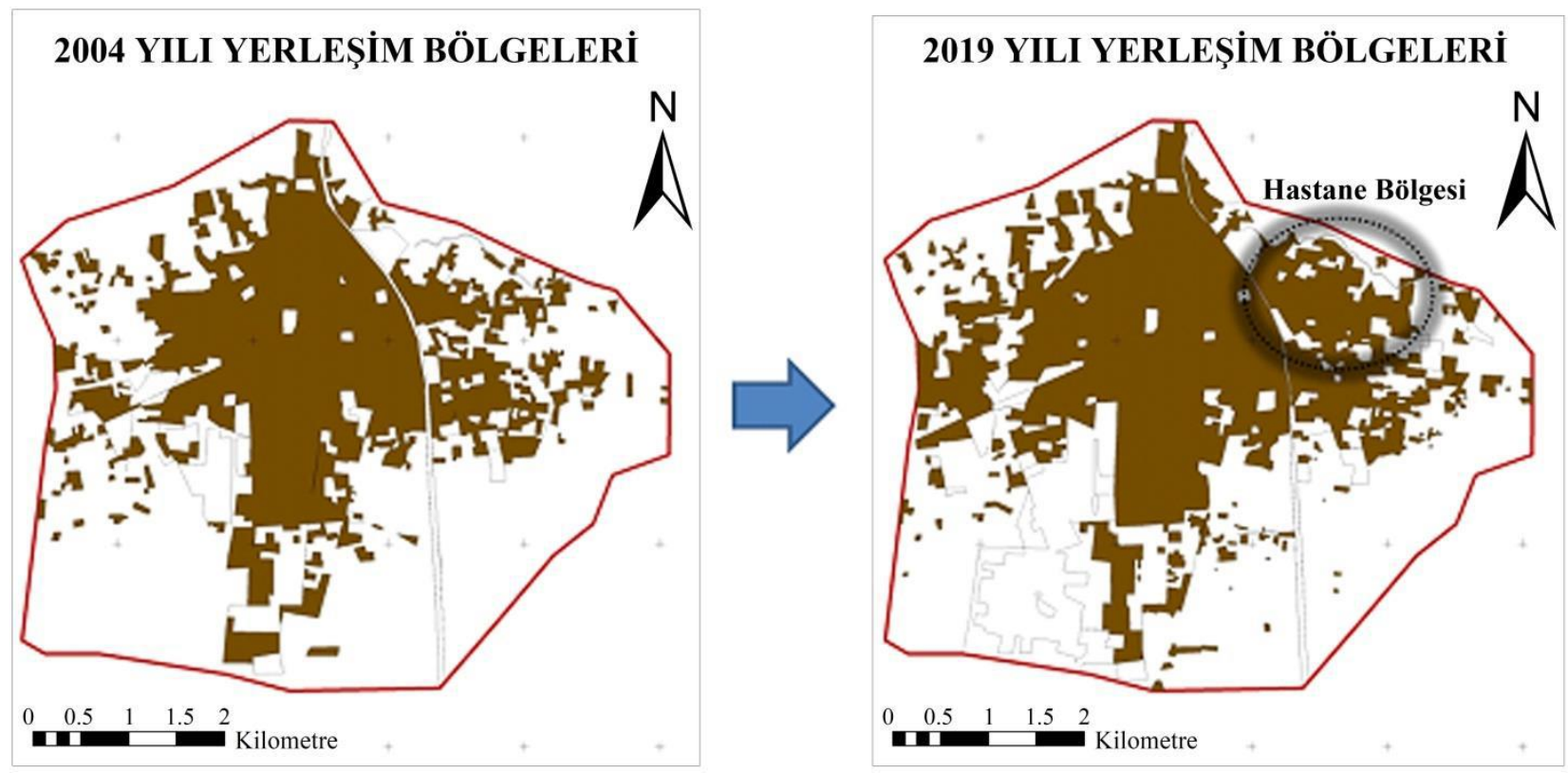

Şekil 3. 2004 yerleşim bölgeleri (solda), 2019 yerleşim bölgeleri (sağda)

Sanayi alanları için, 2004-2019 yılları arasında incelenen alan kullanımlarının değişim analizine göre; sanayi alanların \% 4,94 oranında arttığı görülmektedir. Nüfus artışı ve hızlı kentleşmenin etkisi ile verimli tarım alanları yok edilerek, bu bölgeler sanayi alanlarına dönüştürülmüştür. Bölgedeki sanayi alanları, 2012 yılında yapımına başlanan Nazilli Organize Sanayi Bölgesi ile de artış göstermiştir (Şekil 4).

İlçede bulunan yeşil alan varlığı incelendiğinde yeşil alanların, 2004-2019 yılları arasında sanayi ve yerleşim alanlarının artmasından dolayı azalması gerekirken, yapılan park ve yeşil alan çalışmaları neticesinde $\% 4,12$ oranında arttı̆̆ belirlenmiştir.

Türkiye'de yapılan AÖ/AK değişimini inceleyen diğer çalışmalar incelendiğinde özellikle Nazilli ilçesinden daha büyük yüzölçümüne sahip alanlarda, tarım alanları ve yeşil alanların azaldığı, yerleşim alanlarının ise arttığı görülmüştür. Nazilli ilçesinde ise yerleşim alanlarına ek olarak sanayi alanlarının artış göstermesi bölgedeki ekolojik/çevresel baskıyı artırırken, yeşil alanların artması ise bu baskıyı az da olsa azaltmaktadır. 

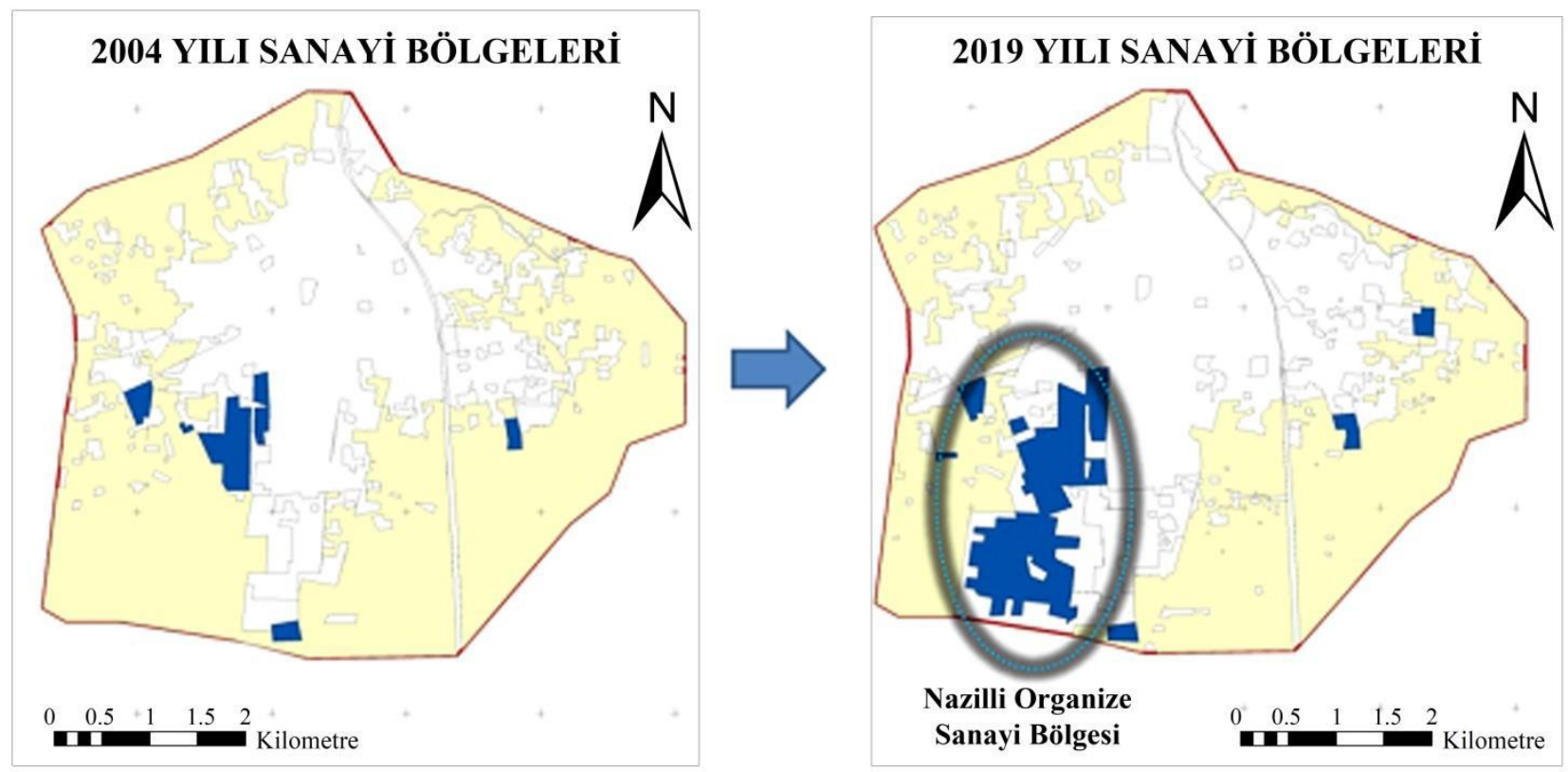

Şekil 4. 2004 yılı sanayi bölgesi (solda), 2019 yılı sanayi bölgesi (sağda)

\section{SONUÇ:}

Bu çalışmada, Aydın ili Nazilli ilçe sınırlarına giren yaklaşık olarak 2918,97 ha'lık çalışma alanına ait 2004 ve 2019 tarihli uydu görüntüleri kullanılmış, coğrafi bilgi sistemleri kullanılarak arazi kullanımı/arazi örtüsü (AK/AÖ) üzerinde meydana gelen değişim ile durum analiz edilmiş ve karşılaştıılmıştır. 2004-2019 yılları arasında incelenen alan kullanımları değişiminde sanayi alanları, yerleşim alanları ve yeşil alanların arttığı, tarımsal alanların ve sulak alanların azaldığı tespit edilmiştir. Gerçekleşen nüfus artışı ve hızlı kentleşmenin etkisi ile verimli tarım alanları yok edilerek sanayi alanlarına ve yerleşim alanlarına dönüştürülmüştür.

Sanayi alanlarında gerçekleşen \% 4,95 (144,41ha)'lık değişimde tarım alanlarının eskisi gibi kullanılmaması, Nazilli ilçesinde organize sanayi bölgesi kurulmak istenmesi ve merkez bölgede bulunan devlet hastanesinin şehir merkezinin dışına taşınması etkili olmuştur.

Devlet hastanesinin şehir dışına taşınmasıyla birlikte bölgede bulunan tarım alanları imara açılıp yerleşim bölgesine dönüştürülmüştür. Yerleşim alanlarında gerçekleşen \%4,90 (143,07ha)'lık artışta devlet hastanesinin taşınması oldukça etkili olmuştur.

Türkiye'de yapılan AÖ/AK değişimini inceleyen diğer çalışmalar (Oğuz ve Zengin, 2011; Gülersoy, 2013b; Bayar ve Karabacak, 2017) incelendiğinde özellikle Nazilli'den büyük olan yerlerde tarım alanları ve yeşil alanların azaldığı, buna karşın, yerleşimlerin arttığı görülmüştür. Nazilli'de ise yerleşime ek olarak yeşil alanların arttı̆̆ gözlemlenmiştir

Nazilli ilçesinde arazi örtüsü sınıflandırılmasına göre, 2004-2019 yılları arasında tarım alanları, yerleşim alanları, sanayi alanları, sulak alanlar ve yeşil alanlar arasındaki sıralama değişmemiş̧ir. Ortaya çıkan değişim miktarları dikkate alındığında Nazilli ilçesinde ilerleyen süreçte yerleşim ve sanayi alanlarının, tarım ve yeşil alanlar üzerinde olan baskısını giderek artacağı ve tarımsal alanlarda gerçekleşen tahribatın artacağı düşünülebilir.

Sonuç olarak; bu çalışma, AÖ/AK değişimleri hakkında bilgi sağlamasının yanında, mekânsal değişimlerin uzaktan algılama teknikleri yoluyla analiz edilmesi, değerlendirilmesi ve izlenmesinde bir rehber olarak görev yapmaktadır.

Araştırmanın sonucundaki önerilerimiz; 
İlçenin merkezinin içinden geçen akarsu hattının her iki yanında yeşil bir koridor oluşturulmasıyla kent için mevcut yeşil alanların birbiriyle bağlantısı sağlanabilir.

Kent içi yeşil alan miktarı arttırılarak yeşil alanların homojen dağılımı sağlanabilir.

Hastane yerleşkesi ve çevresindeki yapılaşmanın etkisi ile bölgede tarım alanlarının azaldığı görülmüştür. Bu nedenle yerleşim alanları mevcut sınırlar içerisinde kontrol altında tutularak tarım alanlarına sıçraması engellenebilir.

Tarım alanlarının 15 yıllık periyotta sanayi alanına dönüşmesi ile bu alanlar tahrip edilmiştir. Mevcut sanayi alanının etrafında koruma zonu oluşturularak bu alanların doğal sınırlara ve tarım alanlarına olan baskısı azaltılabilir.

Günümüzde arazi örtüsündeki değişimler, beraberinde iklim değişikliği, biyolojik çeşitliliğin azalması, su-toprak-hava kirliliği gibi nüfus artışına bağlı çevresel problemleri doğurmaktadır. Son yıllarda çevre üzerinde görülen bu olumsuz gelişmeler, bir yandan temel kaynakların üretimini sürdürürken, diğer taraftan arazi örtüsü değişiminin olumsuz sonuçlarını izlemeyi ve koordinasyonunu sağlamayı zorunlu hale getirmiştir. Dünya genelinde gündemde olan koruma-kullanma dengesini sağlama çabaları, birtakım araştırmacıların ve politikacıların öncelikleri arasında yer almaya devam etmektedir (Erle ve Pontius, 2007).

Küreselleşme anlayışının dayattığı sanayileşme, kentleşme gibi antropojenik etkiler ve bunların meydana getirdiği küresel ısınma, iklim değişikliği, kuraklık gibi ekolojik problemleri anlamak ve tanımlayabilmek açısından, gün geçtikçe negatif yönde değişen arazi kullanımlarını analiz etmek çok önemlidir. Tıpkı bu çalışmada da hedeflendiği gibi, bu analizler sayesinde, alan kullanımlarının peyzajı nasıl etkilediği, çevre konusunda literatürün gözden geçirilerek hangi çevresel politikaların oluşturulması gerektiği ve peyzaj bozulmalarını önlemek için hangi kararların alınmasının zorunlu olduğu kavranabilecektir.

Bu çalışmada alana ilişkin genel bir çözüm yaklaşımında bulunulmuştur ancak doğru bir kentsel planlama için detaylı planlama çalışmalarının gerçekleştirilmesi gerekmektedir.

Çıkar Çatışması: Yazarlar herhangi bir çıkar çatışması bulunmamaktadır.

Etik Kurul İzni: Bu çalışma için etik kurul iznine gerek yoktur

\section{KAYNAKÇA:}

Antrop, M. (2000). "Background concepts for integrated landscape analysis". Agric Ecosyst Environ 77:17-28.

Bayar, R., \& Karabacak, K. (2017). “Ankara İli Arazi Örtüsü Değişimi (2000-2012).” Coğrafi Bilimler Dergisi, 15(1), 59-76.

Cürebal, İ., Efe, R., Soykan, A., \& Sönmez, S. (2008). “Balıkesir Kent Merkezi Yerleşim Alanı İle Jeomorfolojik Birimler Arasındaki İlişkinin CBS Ve UA Yöntemleriyle Belirlenmesi.” Ulusal Jeomorfoloji Sempozyumu Bildiriler Kitapçı̆̆g (20-23 Ekim 2008).

ÇŞB (2020). Aydın Nazilli İlçesi Genel Bilgileri. Çevre ve Şehircilik Bakanlı̆̆ı, Aydın Valiliği Çevre ve Şehircilik İl Müdürlüğü, https://aydin.csb.gov.tr/ilceleri-i-1112 (Erişim Tarihi: 21.04.2020).

Dengiz, O. (2011). “'Samsun İlinin Potansiyel Tarım Alanlarının Genel Dağılımları Ve Toprak Etüd Ve Haritalama Çalı̧̧malarının Önemi."’ Anadolu Tarım Bilimleri Dergisi, 26(3), 241-250.

Deniz, M. (2013). "Nazilli İlçesinin Beşeri Ve Ekonomik Coğrafyası." Yayınlanmamış Doktora Tezi, Uşak Üniversitesi Sosyal Bilimler Enstitüsü. 
Ding, J., Jiang, Y., Fu, L., Liu, Q., Peng, Q., \& Kang, M. (2015). "Impacts of land use on surface water quality in a subtropical River Basin: A case study of the Dongjiang River Basin, Southeastern China.” Water, 7(8), 4427-4445.

Ellis, E., \& Pontius, R. (2007). “Land-use and land-cover change.'” Encyclopedia of earth, 1-4.

Everest, T. (2011). “A Arazi Kullanım Etkinliğinin Değerlendirilmesi: Edirne İli Havsa İlçesi Örneği. '’Anadolu Tarım Bilimleri Dergisi, 26(3), 251-257.

Gülersoy, A. E. (2008). “Bakırçay Havzası'nda Doğal Ortam Koşulları İle Arazi Kullanımı Arasındaki İlişkiler', (Doctoral dissertation, DEÜ Eğitim Bilimleri Enstitüsü).

Gülersoy, A. E. (2013a). “Farklı Uzaktan Algılama Teknikleri Kullanılarak Arazi Örtüsü/Kullanımında Meydana Gelen Değişimlerin İncelenmesi: Manisa Merkez İlçesi Örneği (1986-2010).’ Turkish Studies Academic Journal, 8, 1915-1934.

Gülersoy, A. E. (2013b). “Marmara Gölü yakın çevresindeki arazi kullanım faaliyetlerinin zamansal değişimi (19752011) ve göl ekosistemlerine etkileri." Türk Coğrafya Dergisi, (61), 31-44.

Güre, M., Özel, M. E., \& Özcan, H. (2009). “CORINE Arazi Kullanımı Sınıflandırma Sistemine Göre Çanakkale İli.',

Kara, F., \& Karatepe, A. (2012). “Uzaktan Algılama Teknolojileri İle Beykoz İlçesi (1986-2011) Arazi Kullanımı Değişim Analizi.' Marmara Coğrafya Dergisi, (25), 378-389.

Khan. J.H, Parveen. S. \& Ahmed. N. (2015). "Regional Analysis of Sanitation Facilities in Uttar Pradesh." Journal of Humanities and Social Sciences, (IOSR-JHSS), 20(10), 48-56.

KHGM, 2001. Uzaktan Algılama Teknikleri Kullanılarak Arazi Kullanım Sınıfları Tespiti Çalışması. Köy Hizmetleri Genel Müdürlüğü, Toprak ve Su Kaynakları Ulusal Bilgi Merkezi, 176 s., Ankara.

Kurt, S., Demirci, A., \& Karaburun, A. (2010). “İstanbul Kıyılarında 1987 Ve 2007 Y1lları Arasında Arazi Kullanımında Meydana Gelen Değişimler.’’ Doğu Coğrafya Dergisi, 16(26), 115-128.

MGM (2020). Aydın Nazilli İlçesi İklim Bilgileri. Meteoroloji Genel Müdürlüğü, https://www.mgm.gov.tr/iklim/iklim-siniflandirmalari.aspx?m=NAZILLI (Erişim Tarihi: 21.04.2020).

Oğuz, H., \& Zengin, M. (2011). “Peyzaj Patern Metrikleri Ve Landsat 5 Tm Uydu Görüntüleri Kullanılarak Arazi Örtüsü/Arazi Kullanımı Değişimi Analizi (1984-2010): Kahramanmaraş Örneği’’ I. Ulusal Akdeniz Orman ve Çevre Sempozyumu, 26-28.

Parveen, S., Basheer, J., \& Praveen, B. (2018). “A Literature Review On Land Use Land Cover Changes.” Int. J. Adv. Res. 6(7), 1-6.

Praveen, B. (2017). "Monitoring and Assesment of Landslide from Agastmuni To Sonprayag." International Journal of Recent Research in Social Sciences and Humanities (IJRRSSH), 4(2), 92-118.

Richards John, A., \& Xiuping, J. (1999). “Remote Sensing Digital Image Analysis: An Introduction.”

Sala, O. E., Chapin, F. S., Armesto, J. J., Berlow, E., Bloomfield, J., Dirzo, R., ... \& Leemans, R. (2000). “Global biodiversity scenarios for the year 2100." Science, 287(5459), 1770-1774.

Steiner, F. (2016). "Human ecology. How nature and culture shape our World”. Island Press, Washington DC.

Trimble, S. W., \& Crosson, P. (2000). “US soil erosion rates--myth and reality.” Science, 289(5477), $248-250$. 
TUIKK (2001). Türkiye Genel Tarım Sayımlarının Geçici Sonuçları. Türkiye İstatistik Kurumu, http://tuik.gov.tr (Erişim Tarihi: 02.09.2019).

TUIK (2020). Aydın Nazilli İlçesi Toplam Nüfus Bilgileri. Türkiye İstatistik Kurumu, https://biruni.tuik.gov.tr/medas/?kn=95\&locale=tr (Erişim Tarihi: 20.04 .2020$)$.

Vitousek, P. M., Mooney, H. A., Lubchenco, J., \& Melillo, J. M. (1997). "Human domination of Earth's ecosystems. “ Science, 277(5325), 494-499. 